Article

\title{
Potential Protein and Biodiesel Sources from Black Soldier Fly Larvae: Insights of Larval Harvesting Instar and Fermented Feeding Medium
}

\author{
Chung-Yiin Wong ${ }^{1,2, *}$, Siti-Suhailah Rosli ${ }^{1,2}$, Yoshimitsu Uemura ${ }^{2}$, Yeek Chia Ho ${ }^{3}$, \\ Arunsri Leejeerajumnean ${ }^{4}$, Worapon Kiatkittipong $\left.{ }^{5}{ }^{(}\right)$, Chin-Kui Cheng ${ }^{6}$, Man-Kee Lam ${ }^{7}$ \\ and Jun-Wei Lim 1,2,*(D) \\ 1 Department of Fundamental and Applied Sciences, Universiti Teknologi PETRONAS, Seri Iskandar 32610, \\ Perak Darul Ridzuan, Malaysia; suhailah9875@gmail.com \\ 2 Centre for Biofuel and Biochemical Research, Institute of Self-Sustainable Building, Universiti Teknologi \\ PETRONAS, Seri Iskandar 32610, Perak Darul Ridzuan, Malaysia; yoshimitsu_uemura@utp.edu.my \\ 3 Department of Civil and Environmental Engineering, Universiti Teknologi PETRONAS, Seri Iskandar 32610, \\ Perak Darul Ridzuan, Malaysia; yeekchia.ho@utp.edu.my \\ 4 Department of Food Technology, Faculty of Engineering and Industrial Technology, Silpakorn University, \\ Nakhon Pathom 73000, Thailand; LEEJEERAJUMNEAN_A@su.ac.th \\ 5 Department of Chemical Engineering, Faculty of Engineering and Industrial Technology, \\ Silpakorn University, Nakhon Pathom 73000, Thailand; KIATKITTIPONG_W@su.ac.th \\ 6 Faculty of Chemical and Natural Resources Engineering, Universiti Malaysia Pahang, Lebuhraya Tun Razak, \\ Gambang 26300, Pahang, Malaysia; chinkui@ump.edu.my \\ 7 Department of Chemical Engineering, Universiti Teknologi PETRONAS, Seri Iskandar 32610, Perak Darul \\ Ridzuan, Malaysia; lam.mankee@utp.edu.my \\ * Correspondence: johnsonwcy@gmail.com (C.-Y.W.); junwei.lim@utp.edu.my (J.-W.L.)
}

Received: 10 January 2019; Accepted: 25 February 2019; Published: 25 April 2019

\begin{abstract}
Primarily produced via transesterification of lipid sources, fatty acid methyl ester (FAME) of biodiesel derived from insect larvae has gained momentum in a great deal of research done over other types of feedstock. From the self-harvesting nature of black soldier fly larvae (BSFL), research had, however, only concentrated on the harvest of BSFL on sixth instar. Through rearing BSFL on coconut endosperm waste (CEW), 100 BSFL were harvested at the fifth and sixth instar, then modification on CEW with mixed-bacteria powder was carried out. It was found that the fifth instar BSFL had 34\% lipid content, which was $8 \%$ more than the sixth instar. Both instars had similar corrected protein contents around 35-38\%. The sixth instar BSFL contained around 19\% of chitin, which was about $11 \%$ more than the fifth instar. Biodiesel products from both instars showed no differences in terms of FAME content. With modification on CEW, at $0.5 \mathrm{wt} \%$ of mixed-bacteria powder concentration, the maximum waste-to-biomass conversion (WBC) and protein conversion (PC) were achieved at $9 \%$ and $60 \%$, respectively. Moreover, even with the shorter fermentation time frame of CEW, it did not affect the development of BSFL in terms of its WBC and PC when fed with 14 and 21 days fermented medium. FAME from all groups set, which predominantly constituted about C12:0 at around 60\%, followed by $\mathrm{C} 14: 0$ at around $15 \%, \mathrm{C} 16: 0$, and C18:1 both at 10\% on average. Lastly, the FAME yield from BSFL was improved from 25\% (sixth instar) to 33\% (fifth instar) and showed its highest at 38.5\% with modification on raw CEW with $0.5 \mathrm{wt} \%$ mixed-bacteria powder and fermented for 21 days. Thus, harvesting BSFL at earlier instar is more beneficial and practical, as it improves the FAME yield from the BSFL biomass.
\end{abstract}

Keywords: black soldier fly larvae (BSFL); instar; lipid; fatty acid methyl ester (FAME); fermentation 


\section{Introduction}

In recent years, investigations focusing on oleaginous microorganisms to produce biodiesel have initiated a third-generation biofuel into the renewable energy research realms [1-3]. However, oleaginous microorganism, which is defined as microbial (microalgae, bacterium, yeast, or fungi) with rich lipid content usually exceeding 20\% [4-6] are often apt to be more buoyant or suspended in their cultivation medium, hence resisting settling in [5,7]. This unfortunate scenario has directly incurred high biomass harvesting expenses rising from the intensive time and energy required in handling such large microbial feedstock volume. At times, this accounts for up to approximately $20-30 \%$ of total production cost [8]. Thus, insect-derived biodiesel could be a better choice compared to oleaginous microorganisms to generate biodiesel. The rationale for this is that through insect farming, several biochemical products and by-products can be obtained, including insect-derived lipid, protein, and biodiesel [9]. In addition to that, solid waste could be treated and converted into value added products such as vermicomposting bio-fertilizer, which possess similar performances as conventional fertilizer [10].

Looking from an economical perspective, a rapid increment in global population has forced researchers to find alternative protein sources to sustain global demands. However, common protein from animal sources is not sustainable due to its higher energy input and global warming potential, high emission of green house gas (GHG), higher cost in terms of water and feed consumed, and huge land area requirement. Currently, over 1000 species of insects are used to fulfill protein demand; insects are more viable, as they have higher proficient feed conversion ratio, are able to consume numerous type of feed, and have swift growth rates and shorter life cycles compared to known poultry [11]. In general, insect possess up to 40 to $75 \%$ (dry weight basis) crude protein content, and this value solely depends on the insect species and the stage in their life cycle. Insects could be a food source either consumed raw, processed into fine powder, or integrated into animal feed. Insect diet consists of amino acids, which are greater than common poultry formulation and higher in protein content compared to soybean and conventional fish meal [12]. Of the thousand insect species in question, these demands are met mostly from applying black soldier fly larvae (BSFL) biomass into animal diet to replace common diet meal. Black soldier fly larvae are favored due to their higher protein content and greater amino acid composition [13-16].

Among the insect larvae, several species were investigated to measure their respective performances on biodiesel production, which were flesh fly, superworm, mealworm beetle, housefly, latrine blowfly, soldier fly, and ants [17-23]. Among these insect feedstocks, the usage of BSFL as the feedstock for lipid and protein content had been revealed. BSFL are saprophagous and polyphagous, as they are able to consume decaying matters and a wide variety of biomass [24]. Black soldier fly under the family of Stratiomyidae ranges from yellow, green black, or blue in color, and its appearance mimics the bees or wasps. BSFL stage consists of six instars and lasts for 14-22 days for biomass accumulation, yet the time frame depends on the feed medium and environmental factors as well. BSFL enter the last stage of the larvae stage, known as pre-pupae, where BSFL stop feeding and pupae at the dry surfaces. Pupation may take up to 14 days, and adults normally survive for about 10 days. Mating begins two days after adult emergence, and female BSFL oviposit the eggs at the crevices or cracks. The whole development process of BSF from birth to adulthood might take up to 40-43 days [25]. Lipid fractions of BSFL were determined in a previous study that showed BSFL contained mainly C12:0 (38.43 wt\%), C16:1 (15.71 wt\%), C14:0 (12.33 wt\%), C18:1 (8.81 wt\%) and C18:0 (2.95 wt\%) [26].

Due to the natural self-harvesting ability of BSFL while reaching the pre-pupae stage, they have been widely studied for biodiesel production. During this stage, BSFL have their mouth transformed into a beak-like structure to crawl out from the feeding substrate and pupae on the dry surfaces. This phenomenon is known as the self-harvesting ability, and this process eases the separation of pupae from the feed medium [25]. However, separation and sorting processes are still required to separate pupae from feed residues, exuviae, and pre-pupae. Common ways to separate BSF pupae from the 
diet residue still mainly utilize fine mesh of bamboo baskets, and sorting solely relies on manpower done by hand [27].

Furthermore, BSFL biomass also contains high protein $(\sim 40 \%)$ and lipid ( $30 \%)$ sources [28], which could plausibly be used as aquaculture, poultry, and broilers feed. For example, BSF lipid was introduced into aquaculture feed to promote growth, fatty acid, and lipid deposition in juvenile Jian carp. The results showed that there were no significant differences in growth rate, but the fatty acid composition (mainly C12:0 and C14:0) was visibly affected by the inclusion of BSF lipid. Hence, BSF lipid can be used to replace soybean oil in aquaculture feed since it can be introduced at $100 \%$ composition without any negative impacts on the growth of Jian carp [29]. Besides, alongside BSF lipid, BSF biomass can also be introduced into feed medium to replace common protein sources. Substitution of fish meal protein to defatted BSF biomass did not affect the growth performances of Jian carp, and it boosted the antioxidant status of Jian carp. However, substitution of BSF biomass greater than $75 \%$ in weight percentage caused intestinal damage and dietary stress. Hence, $50 \%$ substitution was recommended from the previous study [30]. Nevertheless, at this point in time, most of the research was performed utilizing BSFL pre-pupae biomass for biodiesel production [23,31,32]. Yet, during the pre-pupae stage, BSFL stopped feeding, and all the metabolic cost depended on the fat body tissues that stored during previous instars.

In Malaysia, the large areas of the palm oil plantation (3.87 million ha.), coconut plantation (147 thousand ha.), etc., have generated large amounts of cellulosic and non-cellulosic waste materials, which are causing environmental problems [33]. Yearly, 0.747 million tons of coconut shells, 0.374 million tons of husks, and 0.35 million tons of coconut copra are produced [34]. This huge amount of agricultural waste goes to landfill, causing soil deterioration and contamination of underground water. Through vermicomposting, these solid wastes can be reduced and transformed into value-added biochemical products. Compared to other types of feeding medium such as food waste, fruit waste, municipal waste, and animal manure, coconut endosperm waste (CEW) was selected as the feed medium in this BSFL experiment due to its year-long availability and easy handling necessities of homogenous quantity. Ultimately, the intention is to reduce waste accumulated in landfill. To that end, the primary objective of this study is to determine the impacts of harvesting periods and the modification of CEW as a feeding medium on BSFL's lipid, protein, and FAME content.

\section{Materials and Methods}

\subsection{Acquisition of Neonate BSFL}

The raw CEW was introduced into the opaque cylindrical plastic container with a diameter of $16.5 \mathrm{~cm}$ and height of $24.5 \mathrm{~cm}$ to serve as a bait. The moisture content of raw CEW was adjusted to $60-70 \%(\mathrm{wt} / \mathrm{wt})$ of dry weight basis, and the thickness of the medium was about $3-5 \mathrm{~cm}$. The corrugated boards were cut into $6 \mathrm{~cm} \times 2 \mathrm{~cm}$ (length $\times$ width) and attached to the inner surface of the plastic container at about $4-6 \mathrm{~cm}$ above the medium, serving as a stand for female black soldier fly to oviposit eggs. The baits were placed at the natural vegetated area and checked every alternate day for BSF egg availability. The attached eggs on the corrugated boards were collected and examined under optical light microscope, as shown in Figure 1. The red dots indicate the head capsule part, and the blunt end indicates the bottom part. The eggs with live BSFL were then transferred to a sterile Petri dish, and the moisture was maintained by a wet filter paper with sterile distilled water and left to undergo eclosion. 
$100 \mu \mathrm{m}$

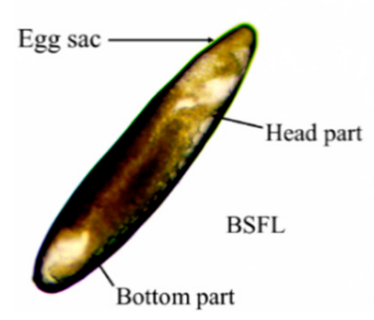

Figure 1. Black soldier fly larvae (BSFL) egg under magnification power of $40 \times$ through optical light microscope.

\subsection{Acquisition of Coconut Endosperm Waste and Its Properties}

Raw CEW was obtained from a local coconut milk seller in Seri Iskandar. Moisture content of raw CEW was determined by gravimetric method. Firstly, $10 \mathrm{~g}$ of raw CEW was weighed and dried at $105^{\circ} \mathrm{C}$ until constant weight was obtained. The moisture content and dry matter were determined using Equations (1) and (2):

$$
\begin{gathered}
\text { Moisture content }(\%)=\left[\left(\mathrm{CEW}_{0}-\mathrm{CEW}_{\mathrm{f}}\right) / \mathrm{CEW}_{0}\right] \times 100 \% \\
\text { Dry matter }(\%)=\left(\mathrm{CEW}_{\mathrm{f}} / \mathrm{CEW}_{0}\right) \times 100 \%
\end{gathered}
$$

where $\mathrm{CEW}_{0}$ represents initial weight and $\mathrm{CEW}_{\mathrm{f}}$ represents final weight of raw $\mathrm{CEW}$, respectively. Next, the nitrogen content of raw CEW was determined using the Dumas method (Perkin Elmer 2400 series). Assuming proteins from coconut ranged from 18.5 to $19 \%$ nitrogen content [35], crude protein was determined by multiplying the total nitrogen content with the conversion factor of 5.30 .

\subsection{Preparation of Raw Coconut Endosperm Waste as Feeding Medium}

Upon the determination of moisture content, the desired amount of distilled water was added to the raw CEW to achieve 70\% moisture content (wt/wt) of dry weight basis. The amount of distilled water needed was calculated using Equation (3):

$$
\mathrm{V}_{\mathrm{H} 2 \mathrm{O}}(\mathrm{mL})=\frac{\left(\mathrm{D}_{\mathrm{H} 2 \mathrm{O}}\right)\left(\mathrm{M}_{\mathrm{S}}\right)}{1-\mathrm{D}_{\mathrm{H} 2 \mathrm{O}}}-\mathrm{M}_{\mathrm{H} 2 \mathrm{O}}
$$

where $\mathrm{V}_{\mathrm{H} 2 \mathrm{O}}$ is the desired amount of distilled water to be added, $\mathrm{D}_{\mathrm{H} 2 \mathrm{O}}$ is the desired proportion of water in the medium, $\mathrm{M}_{\mathrm{S}}$ is the oven dried weight of $100 \mathrm{~g}$ medium, and $\mathrm{M}_{\mathrm{H} 2 \mathrm{O}}$ is the mass of water in $100 \mathrm{~g}$ of oven dried medium [36]. The moisture adjusted CEW was used as a feeding medium to rear the 6 days old BSFL. The feed medium was introduced to 100 BSFL that were kept in a cylindrical container capped with a ventilated lid. The feeding was discontinued when the BSFL reached the fifth and the sixth instar by determining their head sizes and color changes, as indicated in Figure 2 [37]. The collected BSFL were then separated from the residue, water washed, and inactivated at $105^{\circ} \mathrm{C}$ for $5 \mathrm{~min}$ before drying at $60^{\circ} \mathrm{C}$ until constant weight was obtained $[5,23]$. The lipid content, protein content, and chitin content of BSFL at the fifth and the sixth instar were determined. 


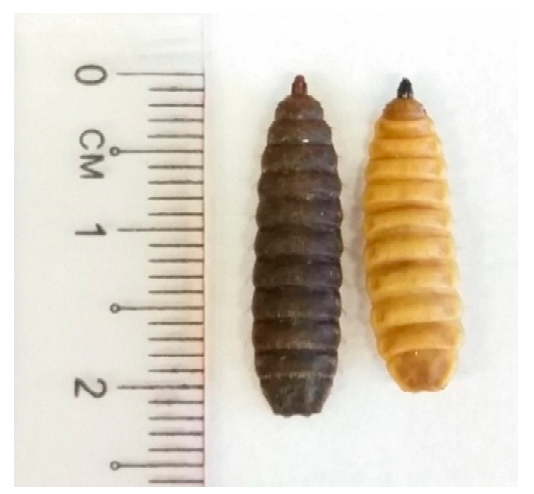

Figure 2. BSFL at the sixth (left) and the fifth (right) instar.

\subsection{Fermented CEW Preparation and BSFL Rearing}

After determining the best harvesting instar stage, a modification of raw CEW was done by introducing different concentrations of mixed-bacterial powder (Reckitt Benckiser, UPN:1920080310) at $0.02,0.5,0.1$, and $2.5 \mathrm{wt} \%$ into CEW and mixed homogenously. The moisture of CEW was adjusted following Equation (3) and transferred into a polyethylene container and capped tightly to facilitate an anoxic fermentation at the sun-shaded area. The fermentation was carried out for 28 days. After fermentation, $10 \mathrm{~g}$ of CEW was administrated to $20 \mathrm{BSFL}$. The rearing was discontinued when the BSFL reached the fifth instar instead of the sixth instar. Then, once the performances of different mixed-bacteria powder concentration on BSFL growth were validated, the selected mixed-bacteria powder concentration was then mixed again with raw CEW with $70 \%$ moisture content and fermented for $7,14,21$, and 24 days before it was administrated to 20 BSFL. The rearing was discontinued once the BSFL reached the fifth instar, and the samples were processed as described earlier. Next, the waste-to-biomass conversion (WBC) of BSFL was calculated using Equation (4) [38].

$$
\mathrm{WBC}(\%)=\frac{\mathrm{BSFL}_{\mathrm{DM}}(\mathrm{g})}{\mathrm{CEW}_{\mathrm{DM}}(\mathrm{g})} \times 100 \%
$$

where $\mathrm{BSFL}_{\mathrm{DM}}$ and $\mathrm{CEW}_{\mathrm{DM}}$ are the total dry matter in the BSFL biomass, and CEW is introduced as feed correspondingly.

\subsection{Biochemical Products Analysis}

\subsubsection{Lipid Extraction}

Lipid from BSFL biomass was extracted using petroleum ether (boiling point at $40-60{ }^{\circ} \mathrm{C}$ ) solvent extraction. Approximately $0.1 \mathrm{~g}$ of grounded dried BSFL biomass was weighed, and $20 \mathrm{~mL}$ petroleum ether was added. The mixture was stirred for $24 \mathrm{~h}$ using a magnetic stirrer. The solvent layer was separated by filtration using filter paper, and the biomass residue was washed with $10 \mathrm{~mL}$ of petroleum ether twice. Then, the solvent layers were combined and dried under rotary evaporator. The extracted BSFL lipid was further dried in an oven at $105^{\circ} \mathrm{C}$ for $1 \mathrm{~h}$ and cooled to room temperature in a desiccator. The weight of dried BSFL lipid was determined using the gravimetric method. The lipid content of BSFL was determined using Equation (5).

$$
\text { Lipid content }(\%)=\left[\operatorname{Lipid}_{\mathrm{BSFL}}(\mathrm{g}) / \text { Biomass }_{\mathrm{BSFL}}(\mathrm{g})\right] \times 100 \%
$$

where $\operatorname{Lipid}_{\mathrm{BSFL}}$ is the total dried weight of BSFL, and Biomass $\mathrm{BSFL}$ is the total dried mass of BSFL used for lipid extraction. 


\subsubsection{Nitrogen Content and Protein Conversion of BSFL}

Nitrogen content of BSFL was determined using the Dumas method (Perkin Elmer 2400 series). Assuming proteins from animal tissue contain 16\% nitrogen content [35], crude protein was determined by multiplying the total nitrogen content with the conversion factor of 6.25 . However, with the presence of chitin in BSFL, which accounted for about $6.89 \%$ of the nitrogen content, the direct protein conversion from total nitrogen might have led to an over-estimation of protein content. In order to recalculate the corrected protein content, chitin contents at the fifth and the sixth were determined [39], and the chitin-derived nitrogen content was subtracted from the total nitrogen content before protein conversion. Then, the amount of protein from CEW being converted to protein in BSFL, known as protein conversion (PC), was determined by Equation (6) [38].

$$
\text { Protein conversion }(\%)=\frac{\text { BSFL }_{\mathrm{DM}}(\mathrm{g}) \times \text { Protein } \mathrm{BSFL}_{\mathrm{DM}}(\%)}{\mathrm{CEW}_{\mathrm{DM}}(\mathrm{g}) \times \operatorname{Protein}_{\mathrm{CEW}}(\%)} \times 100 \%
$$

where BSFLDM and CEW ${ }_{D M}$ are the dry matter of the BSFL and initial CEW introduced, and Protein BSFL $_{D M}$ and Protein CEW $_{\mathrm{DM}}$ are the percentage of crude protein (dry basis) in BSFL and CEW, respectively.

\subsubsection{Esterification and Trans-Esterification, FAME Content Analysis, and FAME Yield}

The extracted lipid then underwent esterification reaction with $1 \% \mathrm{HCl}$ in methanol at $75{ }^{\circ} \mathrm{C}$ for $60 \mathrm{~min}$. The solution was then dried with anhydrous sodium sulphate to remove water produced. The ester and un-esterified lipid was recovered using petroleum ether and underwent trans-esterification reaction with $1 \%$ potassium hydroxide in methanol at $65^{\circ} \mathrm{C}$ for $30 \mathrm{~min}$ [40]. The solution was then washed with $10 \%$ sodium chloride solution, dried with anhydrous sodium sulphate, and stored at $4{ }^{\circ} \mathrm{C}$ prior to gas chromatography (GC) analysis. Analysis of FAME in biodiesel was performed using a Shimadzu model GC-2010 plus system (Shimadzu, Kyoto, Japan) equipped with a polyethylene glycol capillary column BPX-BD20 (SGE, Melbourne, Australia) $(30 \mathrm{~m} \times 0.32 \mathrm{~mm} \times 0.25 \mathrm{~mm}$ ) and a flame ionization detector (Shimadzu, Kyoto, Japan). Helium was used as the carrier gas at a flow rate of $1.72 \mathrm{~mL} / \mathrm{min}$ and a pressure of $83.9 \mathrm{kPa}$. The inlet was operated in split mode (50:1) at a temperature of $250{ }^{\circ} \mathrm{C}$. The column temperature was programmed as follows: Holding at $150{ }^{\circ} \mathrm{C}$ for $1 \mathrm{~min}$, increasing to $240{ }^{\circ} \mathrm{C}$ at $5{ }^{\circ} \mathrm{C} / \mathrm{min}$, and holding at $240^{\circ} \mathrm{C}$ for $6 \mathrm{~min}$. The methyl heptadecanoate (C17:0) was selected as the internal standard (ISTD) in determining the composition of FAME in biodiesel. Accordingly, $1.0 \mathrm{~mL}$ of heptane containing $1.001 \mathrm{mg} / \mathrm{mL}$ of methyl heptadecanoate (ISTD) was added to the vial containing biodiesel. Upon handheld reverse mixing, the mixture was filtered through a PTFE filter with a pore size of $0.20 \mu \mathrm{m}$ before transferring into a GC vial. A sample volume of $1 \mu \mathrm{L}$ was injected into the column, and FAME content in biodiesel was calculated based on Equation (7) [41].

$$
\text { FAME content }(\%)=\frac{\mathrm{A}_{\mathrm{FAME}}}{\mathrm{A}_{\mathrm{ISTD}}} \times \frac{\mathrm{C}_{\mathrm{ISTD}} \times \mathrm{V}_{\mathrm{ISTD}}}{\mathrm{m}} \times 100 \%
$$

where $\mathrm{A}_{\mathrm{FAME}}$ is the peak area of specific FAME, $\mathrm{A}_{\mathrm{ISTD}}$ is the peak area of $\mathrm{C17:0,} \mathrm{C}_{\mathrm{ISTD}}$ is the concentration of $\mathrm{C} 17: 0$, which was $1.001 \mathrm{mg} / \mathrm{mL}, \mathrm{V}_{\text {ISTD }}$ is the volume of $\mathrm{C} 17: 0$, which was $1.0 \mathrm{~mL}$, and $\mathrm{m}$ is the mass of the sample used to mix with C17:0. FAME yield from BSFL biomass was calculated using Equation (8).

$$
\text { FAME yield }(\%)=\left[\text { FAME content } \times \mathrm{M}_{\text {Lipid }}\right] / \mathrm{M}_{\mathrm{BSFL}}
$$

where $\mathrm{M}_{\mathrm{Lipid}}$ is total mass of the lipid and $\mathrm{M}_{\mathrm{BSFL}}$ is total mass of BSFL biomass on dry weight basis.

\subsection{Statistical Analysis}

Throughout this study, all experiments were triplicated, and data for BSFL development under different treatment were analyzed with ANOVA followed by a Tukey Post-hoc pairwise comparison test at a level of significance, $\alpha=0.05$, using the Minitab program (Version 17, Minitab Pty Ltd, NSW, Australia). 


\section{Results and Discussion}

\subsection{Impacts of Harvesting Instar on BSFL's Lipid and Protein Content}

One hundred BSFL were collected from two different instar stages, which were the fifth and the sixth instar. As shown in Table 1, the fifth instar of BSFL contained higher amounts of lipid compared to the sixth instar, which were $34 \%$ and $26 \%$, respectively. This gap potentially occurred because during the fifth instar, BSFL was still in an active ingestion state, allowing it to accumulate more body mass and lipid into its own. Meanwhile, when BSFL reached the sixth instar, its feeding mouthpart transformed into a claw shaped beak for it to migrate from the feeding medium and undergo pupation. At the same time, the digestive tract of BSFL was emptied out, and all of the metabolism cost solely depended on the fat body tissues that accumulated in the previous larvae forms [25]. Generally, the metamorphosis of BSFL from the fifth to the sixth instar can last for weeks; therefore, it would greatly influence the lipid content of BSFL, as parts of it would be used to maintain the BSFL at an active stage.

Table 1. Comparison of lipid, chitin, nitrogen, protein, and corrected protein content between the fifth and the sixth instars.

\begin{tabular}{ccc}
\hline Properties & Fifth Instar & Sixth Instar \\
\hline Lipid content $(\%)$ & $34.23 \pm 0.65$ & $25.88 \pm 0.36$ \\
Chitin content $(\%)$ & $7.61 \pm 0.93$ & $18.62 \pm 1.25$ \\
Nitrogen content $(\mathrm{wt} \%)$ & $6.07 \pm 0.01$ & $7.32 \pm 0.06$ \\
Protein content $(\%)$ & $37.94 \pm 0.09$ & $45.72 \pm 0.40$ \\
Corrected protein content $(\%)$ & $34.66 \pm 0.31$ & $37.70 \pm 0.14$ \\
\hline
\end{tabular}

Moreover, when the nitrogen content was determined, it was found that the sixth instar BSFL contained $7.32 \%$ nitrogen, which was $1.25 \%$ more than the fifth instar. This phenomenon could be explained by the sixth instar containing higher chitin levels compared to the fifth instar, which were at around $19 \%$ and $8 \%$, respectively. Chitin, a polymer of $\left(\mathrm{C}_{8} \mathrm{H}_{13} \mathrm{O}_{5} \mathrm{~N}\right)_{n}$, contains $6.89 \%$ nitrogen, and the Dumas combustion method was practiced to determine the total nitrogen content of the substances. Hence, it was necessary to deduct the percentage of nitrogen from chitin from the total nitrogen content prior to protein conversion calculation to avoid overestimation of protein content. The calculated protein content is referred to as corrected protein content. The corrected protein content of BSFL between the fifth and the sixth instar was approximately $35 \%$ and 38\%, with only a 3\% minor difference.

After the lipid was extracted from BSFL biomass, the residual BSFL biomass could be further processed into animal feed or human consumption as a protein source. As the human population keeps increasing, the living standard is enhanced, and the need for better food, such as protein sources from livestock, is increased too. This greatly impacts the environment-for example, dairy farming generates most of the methane gases that affect the balance of nature and cause global warming. Hence, these BSFL biomass residuals are great candidates to fulfill this niche, since they could be a potential protein source replacement and can be used as feed meal in aquaculture, poultry, broilers, as well as for human consumption. However, chitin should be removed prior to feed administration, as chitin in BSFL biomass might reduce feed intake and nutrient availability in aquaculture (Turbot, African catfish), as it reduces growth performance and nutrient assimilation at lower or higher inclusion rates $[42,43]$. Yet, chitin from BSFL could be further processed into chitosan, which is widely used as biopolymers in biotechnology, pharmaceutical, food, cosmetic, textile, paper, and wastewater treatment industries $[15,44]$.

\subsection{FAME Content, Yield, and Profile of Fifth and Sixth Instar of BSFL}

Extractable lipid from both instars was then esterified and trans-esterified into biodiesel, and the FAME content was determined. It was noted that sample products from both the fifth and the sixth instar had high FAME contents around 97\% and 98\%, respectively. FAME profiles from both sample 
products were analyzed, and it was found that BSFL-derived biodiesel contained mostly C12:0, which accounted for about 50-55\%, followed by $\mathrm{C} 14: 0$ at around 20\%, C16:0 and C18:1 at around 10\%, and little amounts of C6:0, C10:0, C14:1, C16:1, and C18:0. There were very small differences of FAME obtained between the fifth and the sixth instar of BSFL, as shown in Figure 3. However, in terms of the FAME yield, the fifth instar BSFL indicated around 33\%, which was higher than the sixth instar with a difference of around $8 \%$, which was due to the higher lipid content in the fifth instar and that heavier BSFL was harvested at this instar. The total dried biomass for 100 BSFL was $5.24 \mathrm{~g}$ for the fifth instar BSFL, and only $3.70 \mathrm{~g}$ for the sixth instar BSFL.

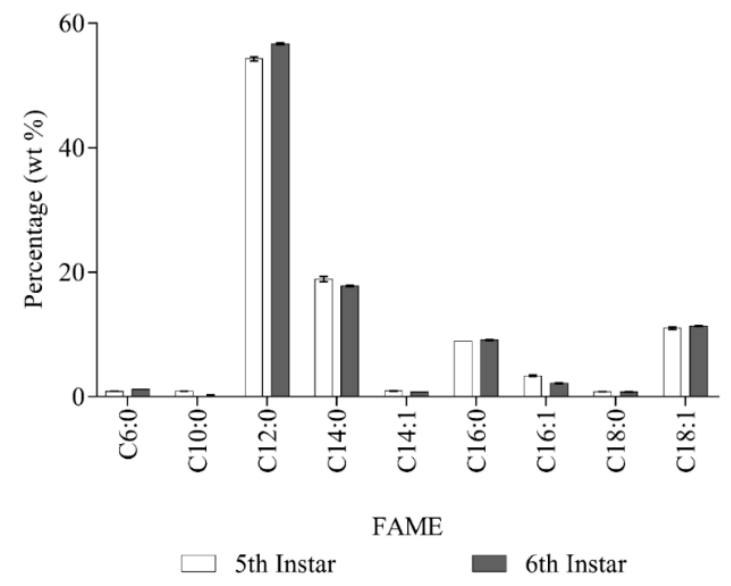

Figure 3. Fatty acid methyl ester (FAME) profile of biodiesel from the fifth and the sixth instar BSFL.

On an industrial scale, to increase yearly product batch and product yield, it is advised to harvest BSFL at the fifth instar since it is more beneficial than harvesting at the sixth instar. Most of the previous studies focused on the self-harvesting ability of BSFL, as they migrate away from the wet feeding medium and go through pupation on dry surfaces [45]. Yet, the current method practiced in the industry today still applies the manual sieving method to separate the larvae from the feeding medium [27]. Thus, it would be more profitable to harvest the BSFL at the fifth instar, as harvesting BSFL in this earlier instar does not affect the fatty acids present in the BSFL biomass much, and both the fifth and the sixth instar would still have to go through the sieving process for BSFL harvesting purposes, and harvesting the fifth instar could be more time and cost effective.

\subsection{Effects of Different Concentrations of Mixed-Bacteria Powder on BSFL Development}

The BSFL development in terms of waste-to-biomass conversion and protein conversion are presented in Figure 4. Under a controlled system with equal raw CEW, the BSFL attained a WBC at around $6 \%$, and this value was increased to around $8 \%$ through a $0.02 \mathrm{wt} \%$ and $0.1 \mathrm{wt} \%$ increment of mixed-bacteria powder concentration. The highest value of WBC was reached only at a higher concentration of mixed-bacteria powder, which was at $0.5 \mathrm{wt} \%$ and showed around $9 \%$. Further increment of mixed-bacteria powder to $2.5 \mathrm{wt} \%$ did not affect much on WBC, as it only dropped a little, to around $8.5 \%$. From this result, it was assumed that at lower concentrations of mixed-bacteria powder, the fermented feed was not mature enough for BSFL consumption, resulting in a low waste-to-biomass conversion [9]. However, a higher mixed-bacteria concentration at $2.5 \mathrm{wt} \%$ led to a decrement in WBC due to the nutrient in fermented raw CEW being consumed by competitive microorganisms. In terms of protein conversion, at the control system, it showed $40 \%$ of PC. This value maintained even with increasing mixed-bacteria powder concentration to $0.02 \mathrm{wt} \%$ and $0.1 \mathrm{wt} \%$. A significant boost of PC could be seen when $0.5 \mathrm{wt} \%$ of mixed-bacteria powder concentration was applied onto raw CEW for fermentation, as it showed around $60 \%$. At the highest concentration of mixed-bacteria powder, the PC decreased with a small amount to around 55\%. It was suggested that the low PC at the control with $0.02 \mathrm{wt} \%$ and $0.1 \mathrm{wt} \%$ of mixed-bacteria powder was due to the fact that the fermented feed was 
only enough for the BSFL to maintain the daily metabolism cost but did not boost growth in terms of protein content. At the concentration of $0.5 \mathrm{wt} \%$, the PC increased $20 \%$ more compared to lower concentrations of mixed-bacteria powder. This could have been due to the fact that the fermented feed was mature and ready for BSFL rearing, which improved their development at the same time. With this, $0.5 \mathrm{wt} \%$ of mixed-bacteria powder was chosen as the optimal concentration for raw CEW fermentation for the following experiment.

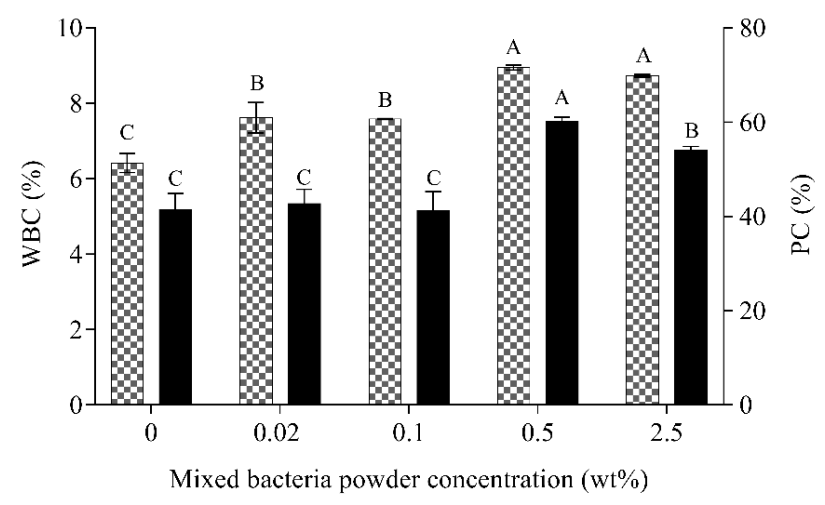

Waste-to-biomass conversion $(\%)$

- Protein conversion $(\%)$

Figure 4. Performance of different concentrations of mixed-bacterial powder on waste-to-biomass and protein conversion when BSFL was fed with fermented CEW. Mean values indicated by same alphabetical letter were not significantly different.

\subsection{Effects of Different Fermentation Time Frame on BSFL Development}

After the validation of the optimal mixed-bacteria powder concentration, the next aim of this study was to shorten the fermentation time frame from the initial 28 days to the proposed time frames, which were 7,14 , or 21 days. Throughout fermentation, a significant number of acid-producing bacteria was found, and it had caused a drop in medium $\mathrm{pH}$, indicating the presence of organic acid. In Figure 5, under the control system, the WBC was initially indicated at $6 \%$, and the value increased to about $6.5 \%$ with an increment of fermentation time frame to seven days. Nevertheless, prolonging the fermentation time frame to 14 days also enhanced the WBC and boosted it to its highest value at around $9 \%$. This value maintained for 21 and 28 days of the fermentation time frame. A similar pattern could be seen in terms of the PC of BSFL fed with different fermentation times of raw CEW under the control system. The PC was only around 35\%, which was the lowest. The PC of BSFL increased to around $50 \%$ when it was fed with seven days fermented raw CEW, and the value lifted to around $60 \%$ and maintained at 14,21 , and 28 days of the fermentation time frame. Figure 5 shows that the WBC and PC both reached their peak conditions when fed with raw CEW fermented at $0.5 \mathrm{wt} \%$ for 14, 21, and 28 days, as the values of WBC and PC could no longer be improved after reaching the maximum point. This occurrence could be plausibly due to the presence of the organic acids that enhanced the gut health and development [46]. Also, through fermentation, part of fibers from CEW could be biotransformed into digestible organic acids, amino acids, and vitamins [27]. However, the nature of raw CEW also played a significant role in limiting the growth performance of BSFL, as it contained a high amount of polymer structures such as cellulose, which was hard to digest even with the introduction of mixed-bacteria powder as the aiding agent. It could also have been due to the low protein content of raw CEW, which was only measured to contain around $1.1 \%$ of nitrogen content, equivalent to $5.83 \%$ of protein content. Other diets such as animal manure and fruits and vegetables waste impact the developmental times of BSFL because the diets are lower in protein and energy with high fat content diet, and too much fat causes the BSFL to face difficulties in breaking down the fat during the metamorphosis [24]. From the previous study, the lipid and protein content of BSFL can be boosted with the introduction of protein sources into the feeding medium [41]. With the co-digestion technique of dairy manure topped with soybean curd residue, it was confirmed that nitrogen content 
reduction was more effective compared to only dairy manure [47]. Thus, a balanced diet in the perspective of energy, fat, protein, carbohydrates, amino acids, vitamins, etc. is required to enhance the development of BSFL as a sustainable source for energy security and food security purposes.

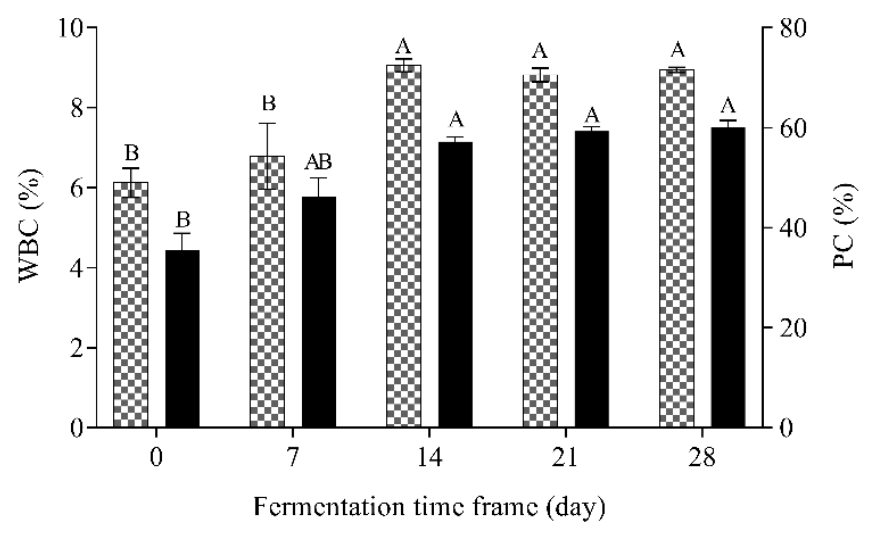

Waste-to-biomass conversion (\%) Protein conversion (\%)

Figure 5. Performance of $0.5 \mathrm{wt} \%$ of mixed-bacterial powder at different fermentation time frames on waste-to-biomass and protein conversion when BSFL was fed with fermented CEW. Mean values indicated by same alphabetical letter were not significantly different.

\subsection{Impacts of Raw CEW Modification on FAME Profile}

Under treatment of raw CEW modification with different concentrations of mixed-bacteria powder and fermentation time frames, the lipid of each group set was trans-esterified into crude biodiesel, and FAME analysis was done. From Figure 6, disregarding the concentration of mixed-bacteria powder, the most abundant FAME was C12:0, followed by C14:0 and C16:0. At the same time, low amounts of $\mathrm{C} 16: 1, \mathrm{C} 18: 2$, and $\mathrm{C} 10: 0$ could be observed in all concentrations of mixed-bacteria powder treatment. However, FAME including C6:0, C14:1, and C18:0 could only be found in certain specific concentrations of mixed-bacteria powder. The possible reason for these results might have been that these fatty acids were already low in concentrations and could not be detected by instrumentation. On the other hand, it could have been that the BSFL used up those types of fatty acids for metabolism cost, but this was a very low possibility compared to the previous reason. Further investigation would be required to determine the changes of fatty acids in BSFL at different instar or ages in order to have a detailed mapping of the changes.

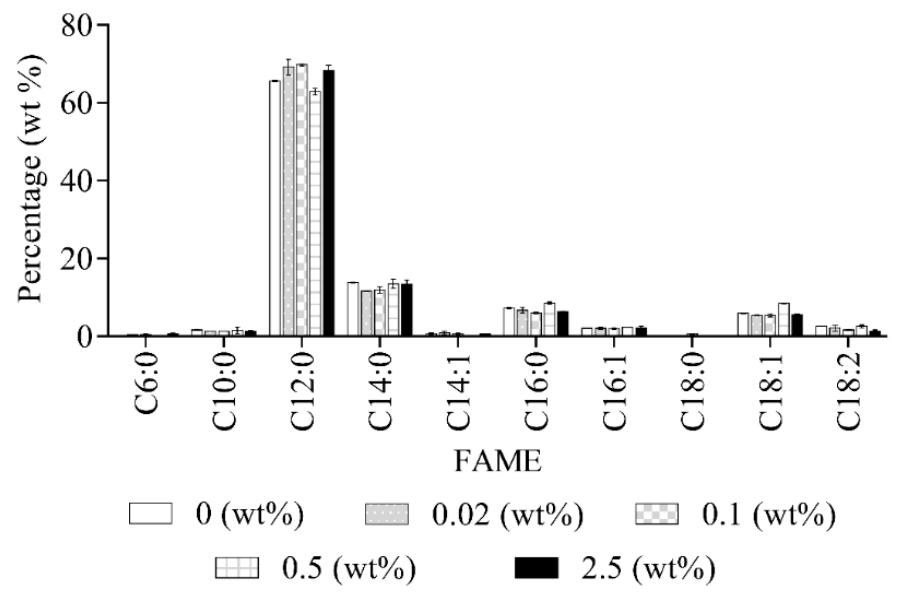

Figure 6. FAME profile of biodiesel from BSFL under different concentrations of mixed-bacterial powder.

Moving forward with the different fermentation time frames, the profile shown in Figure 7 shared a similar pattern with Figure 6. The majority of FAMEs were C12:0, C14:0, C16:0, and C18:1, followed 
by low amounts of C10:0, C16:1, and C18:2. In comparison, it showed that under modification on raw CEW, it did not change the FAME composition or profile of the crude biodiesel derived from BSFL, which could be seen in Figures 6 and 7. Overall, BSFL-derived biodiesel contained 87\% of saturated fatty acids and $13 \%$ of unsaturated fatty acids. First and foremost, the high percentage of long chain saturated fatty acids resulted in poor cold flow property, and the low percentage of unsaturated fatty acids caused a low oxidative stability of the product. Several studies also supported that the BSFL's lipid could be an ideal feedstock for biodiesel production $[23,47]$. Meanwhile, with this modification, the biomass of BSFL was further improved and reached its ultimate when it was fed with raw CEW fermented at $0.5 \mathrm{wt} \%$ for 14 days onwards, as discussed earlier regarding its WBC and PC. In terms of FAME yield, it ranged from its lowest at $35.0 \%$ to its highest at $38.5 \%$, as shown in Table 2 . The FAME yield of BSFL-lipid was slightly influenced $(p>0.05)$ by the modification of raw CEW with a $3.5 \%$ boost, but it was affected at the fifth and the sixth instar, as discussed earlier.

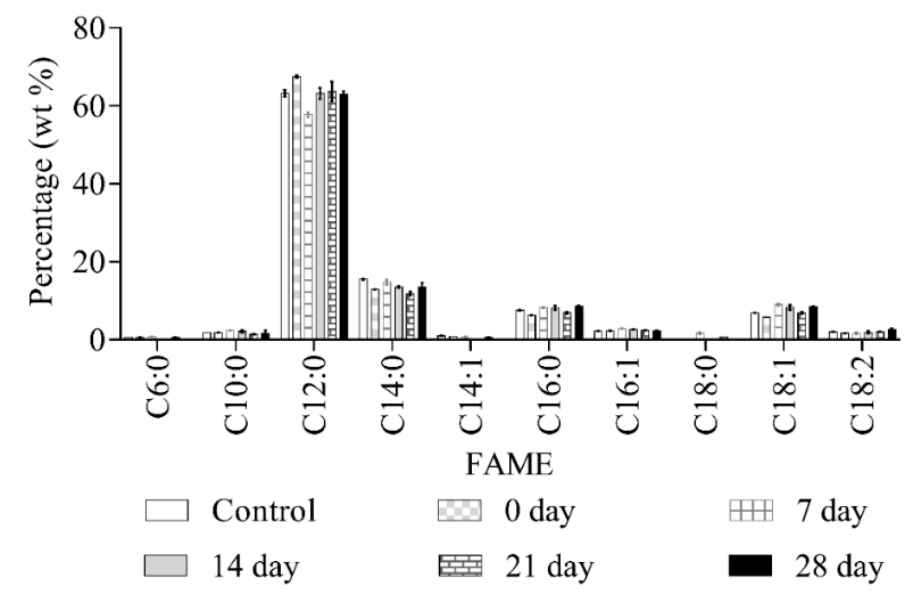

Figure 7. FAME profile of biodiesel from BSFL under $0.5 \mathrm{wt} \%$ of mixed-bacterial powder concentration at different fermentation time frames.

Table 2. FAME yield of BSFL biomass under treated raw coconut endosperm waste.

\begin{tabular}{ccc}
\hline Parameter & Range & FAME Yield (\%) \\
\hline & 0 & 36.4 \\
Mixed-bacteria powder & 0.02 & 35.6 \\
concentration (wt $\%)$ & 0.1 & 36.9 \\
& 0.5 & 37.8 \\
& 2.5 & 37.1 \\
\hline Fermentation time frame (day) & 0 & 35.0 \\
& 7 & 35.0 \\
& 14 & 37.0 \\
& 21 & 38.5 \\
& 28 & 37.8 \\
\hline
\end{tabular}

Moreover, several variables could impact the fatty acids composition in BSFL, including the type of feeding medium, feeding rate, and rearing duration. A detailed FAME composition of crude biodiesel derived from BSFL reared on $0.5 \mathrm{wt} \%$ fermented raw CEW for 14 days was tabulated in Table 3, and a comparison was made with other studies. In this study, the highest percentage of FAME was C12:0, which was $63.1 \%$, and it was also the highest compared to other studies that fed BSFL with food waste, rice straw with restaurant waste, and dairy manure. Moreover, the second most abundant FAME was C14:0 at 13.5\%, which was also the highest compared with food waste and rice straw with restaurant waste. However, it was not detected in the crude biodiesel derived from BSFL fed with dairy manure. On the other hand, BSFL fed with other types of waste had higher compositions of C16:0 and C18:1 with huge differences compared to the findings in this study. Surprisingly, when BSFL 
was fed with rice straw, restaurant waste, and dairy manure, odd numbered FAMEs such as C15:0, C17:1, C19:0, and C19:1 could be found. It can be suggested that BSFL might be able to assimilate the fatty acids present in the feeding medium and incorporate them into its own fatty acids for later use, but further investigation is still required to determine the changes of FAME composition in BSFL when fed with different feeding mediums.

Table 3. Comparison of FAME profile from BSFL-derived biodiesel fed with different feeding mediums.

\begin{tabular}{ccccc}
\hline $\begin{array}{c}\text { Fatty Acid } \\
\text { Methyl Ester }\end{array}$ & This Study & Food Waste [48] & $\begin{array}{c}\text { Rice Straw \& } \\
\text { Restaurant Waste [49] }\end{array}$ & Dairy Manure [50] \\
\hline C10:0 & 2.2 & n/a & 3.8 & 3.1 \\
C12:0 & 63.1 & 44.9 & 27.8 & 35.6 \\
C14:0 & 13.5 & 8.3 & 8.1 & n/a \\
C14:1 & n/a & n/a & n/a & 7.6 \\
C15:0 & n/a & n/a & 1.5 & 1.0 \\
C16:0 & 8.2 & 13.5 & 14.2 & 14.8 \\
C16:1 & 2.7 & 2.4 & 4.5 & 3.8 \\
C17:0 & n/a & n/a & 0.8 & n/a \\
C18:0 & n/a & 2.1 & 7.6 & 3.6 \\
C18:1 & 8.3 & 12.0 & 22.5 & 23.6 \\
C18:2 & 2.0 & 9.9 & 1.8 & 2.1 \\
C18:3 & n/a & 0.1 & 2.1 & n/a \\
C19:0 & n/a & n/a & 1.7 & n/a \\
C19:1 & n/a & n/a & n/a & 1.4 \\
C22:1 & n/a & n/a & n/a & 1.4 \\
\hline
\end{tabular}

Note: The n/a stands for not reported.

\section{Conclusions}

To quicken the bioconversion process, harvesting the BSFL at the fifth instar did impact the lipid and total biomass gained from the larvae, since the sixth instar BSFL had to utilized the stored fat body tissues to sustain their metabolism. At the same time, harvesting the BSFL at the earlier instar did not affect the distribution of FAME, which was targeted for biodiesel production. Additionally, modification of raw CEW was carried out through the introduction of mixed-bacteria powder at different concentrations, and it showed that at a concentration of $0.5 \mathrm{wt} \%$, the WBC and PC achieved their maximum points, which were around $9 \%$ and $60 \%$, respectively. Next, the fermentation time frame was reduced from 28 days to 14 days at $0.5 \mathrm{wt} \%$ mixed-bacteria concentration and did not affect the development of BSFL in terms of its WBC and PC. With the modification of raw CEW, there was a minor impact on the FAME compositions, yet the most abundant FAME was C12:0 at around 60\%, followed by $\mathrm{C} 14: 0$ at around 15\%, and both C16:0 and C18:1 at about 10\% on average. Lastly, the FAME yield from BSFL was improved from $25 \%$ (sixth instar) to $33 \%$ (fifth instar) and showed its highest at $38.5 \%$ with the modification of raw $\mathrm{CEW}$ with $0.5 \mathrm{wt} \%$ mixed-bacteria powder and fermentation for 21 days.

Author Contributions: Conceptualization, C.-Y.W., S.-S.R.; Data curation, C.-Y.W., S.-S.R.; Formal analysis, C.-Y.W.; Methodology, C.-Y.W.; Supervision, Y.U., J.-W.L.; Writing—original draft, C.-Y.W.; Writing—review \& editing, Y.C.H., A.L., W.K., C.-K.C., M.-K.L.

Funding: This research was funded by YUTP-FRG and The Murata Science Foundation.

Acknowledgments: The financial support from Universiti Teknologi PETRONAS via Graduate Assistantship Scheme (GA) to Chung-Yiin Wong is gratefully acknowledged. Also, Jun-Wei Lim wishes to thank the research fundings provided by YUTP-FRG and The Murata Science Foundation.

Conflicts of Interest: The authors declare no conflict of interest. 


\section{References}

1. Allen, E.; Wall, D.M.; Herrmann, C.; Xia, A.; Murphy, J.D. What is the gross energy yield of third generation gaseous biofuel sourced from seaweed? Energy 2015, 81, 352-360. [CrossRef]

2. Srinophakun, P.; Thanapimmetha, A.; Rattanaphanyapan, K.; Sahaya, T.; Saisriyoot, M. Feedstock production for third generation biofuels through cultivation of arthrobacter ak19 under stress conditions. J. Clean. Prod. 2016, 142, 1259-1266. [CrossRef]

3. Lam, M.K.; Yusoff, M.I.; Uemura, Y.; Lim, J.W.; Khoo, C.G.; Lee, K.T.; Ong, H.C. Cultivation of Chlorella vulgaris using nutrients source from domestic wastewater for biodiesel production: Growth condition and kinetic studies. Renew. Energy 2017, 103, 197-207. [CrossRef]

4. Sitepu, I.R.; Sestric, R.; Ignatia, L.; Levin, D.; German, J.B.; Gillies, L.A.; Almada, L.A.G.; Boundy-Mills, K.L. Manipulation of culture conditions alters lipid content and fatty acid profiles of a wide variety of known and new oleaginous yeast species. Bioresour. Technol. 2013, 144, 360-369. [CrossRef]

5. Pinzi, S.; Leiva, D.; López-García, I.; Redel-Macías, M.D.; Dorado, M.P. Latest trends in feedstocks for biodiesel production. Biofuel Bioprod. Biorefin. 2014, 8, 126-143. [CrossRef]

6. Cea, M.; Sangaletti-Gerhard, N.; Acuña, P.; Fuentes, I.; Jorquera, M.; Godoy, K.; Osses, F.; Navia, R. Screening transesterifiable lipid accumulating bacteria from sewage sludge for biodiesel production. Biotechnol. Rep. 2015, 8, 116-123. [CrossRef]

7. Gerardo, M.L.; Den-Hende, S.V.; Vervaeren, H.; Coward, T.; Skill, S.C. Harvesting of microalgae within a biorefinery approach: A review of the developments and case studies from pilot-plants. Algal Res. 2015, 11, 248-262. [CrossRef]

8. Singh, M.; Shukla, R.; Das, K. Harvesting of microalgal biomass. In Biotechnological Applications of Microalgae-Biodiesel and Value-Added Products; Bux, F., Ed.; Taylor and Francis Group: Boca Raton, FL, USA, 2013; pp. 77-88.

9. Mohd-Noor, S.-N.; Wong, C.-Y.; Lim, J.-W.; Uemura, Y.; Lam, M.-K.; Ramli, A.; Bashir, M.J.; Tham, L. Optimization of self-fermented period of waste coconut endosperm destined to feed black soldier fly larvae in enhancing the lipid and protein yields. Renew. Energy 2017, 111, 646-654. [CrossRef]

10. Choi, Y.; Choi, J.; Kim, J.; Kim, M.; Kim, W.; Park, K.; Bae, S.; Jeong, G. Potential usage of food waste as natural fertilizer after digestion by Hermetia illucens (diptera: Stratiomyidae). Int. J. Ind. Entomol. 2009, 19, 171-174.

11. Gahukar, R. Chapter 4-Edible insects farming: Efficiency and impact on family livelihood, food security, and environment compared with livestock and crops. In Insects as Sustainable Food Ingredients; Elsevier: Amsterdam, The Netherlands, 2016; pp. 85-111.

12. Kelemu, S.; Niassy, S.; Torto, B.; Fiaboe, K.; Affognon, H.; Tonnang, H.; Maniania, N.; Ekesi, S. African edible insects for food and feed: Inventory, diversity, commonalities and contribution to food security. J. Insects Food Feed 2015, 1, 103-119. [CrossRef]

13. Maurer, V.; Holinger, M.; Amsler, Z.; Früh, B.; Wohlfahrt, J.; Stamer, A.; Leiber, F. Replacement of soybean cake by Hermetia illucens meal in diets for layers. J. Insects Food Feed 2016, 2, 83-90. [CrossRef]

14. Tomberlin, J.; Van Huis, A.; Benbow, M.; Jordan, H.; Astuti, D.; Azzollini, D.; Banks, I.; Bava, V.; Borgemeister, C.; Cammack, J. Protecting the environment through insect farming as a means to produce protein for use as livestock, poultry, and aquaculture feed. J. Insects Food Feed 2015, 1, 307-309. [CrossRef]

15. Veldkamp, T.; Van Duinkerken, G.; Van Huis, A.; Lakemond, C.; Ottevanger, E.; Bosch, G.; Van Boekel, T. Insects as a Sustainable Feed Ingredient in Pig and Poultry Diets: A Feasibility Study; Wageningen UR Livestock Research: Wageningen, The Netherlands, 2012.

16. Schiavone, A.; Cullere, M.; De Marco, M.; Meneguz, M.; Biasato, I.; Bergagna, S.; Dezzutto, D.; Gai, F.; Dabbou, S.; Gasco, L. Partial or total replacement of soybean oil by black soldier fly larvae (Hermetia illucens L.) fat in broiler diets: Effect on growth performances, feed-choice, blood traits, carcass characteristics and meat quality. Ital. J. Anim. Sci. 2017, 16, 93-100. [CrossRef]

17. Yang, S.; Li, Q.; Zeng, Q.; Zhang, J.; Yu, Z.; Liu, Z. Conversion of solid organic wastes into oil via boettcherisca peregrine (diptera: Sarcophagidae) larvae and optimization of parameters for biodiesel production. PLoS ONE 2012, 7, e45940. [CrossRef]

18. Leung, D.; Yang, D.; Li, Z.; Zhao, Z.; Chen, J.; Zhu, L. Biodiesel from zophobas morio larva oil: Process optimization and fame characterization. Ind. Eng. Chem. Res. 2012, 51, 1036-1040. [CrossRef] 
19. Yang, S.; Liu, Z. Pilot-scale biodegradation of swine manure via chrysomya megacephala (fabricius) for biodiesel production. Appl. Energy 2014, 113, 385-391. [CrossRef]

20. Bowling, J.J.; Anderson, J.B.; Armbrust, K.L.; Hamann, M.T. Evaluation of potential biodiesel feedstock production from oleaginous insect solenopsis sp. Fuel 2014, 117, 5-7. [CrossRef]

21. Zheng, L.; Hou, Y.; Li, W.; Yang, S.; Li, Q.; Yu, Z. Exploring the potential of grease from yellow mealworm beetle (tenebrio molitor) as a novel biodiesel feedstock. Appl. Energy 2013, 101, 618-621. [CrossRef]

22. Yang, S.; Li, Q.; Gao, Y.; Zheng, L.; Liu, Z. Biodiesel production from swine manure via housefly larvae (musca domestica L.). Renew. Energy 2014, 66, 222-227. [CrossRef]

23. Li, Q.; Zheng, L.; Cai, H.; Garza, E.; Yu, Z.; Zhou, S. From organic waste to biodiesel: Black soldier fly, Hermetia illucens makes it feasible. Fuel 2011, 90, 1545-1548. [CrossRef]

24. Nguyen, T.T.X.; Tomberlin, J.K.; Vanlaerhoven, S. Influence of resources on Hermetia illucens (diptera: Stratiomyidae) larval deveopment. J. Med. Entomol. 2013, 50, 898-906. [CrossRef]

25. Diclaro, J.W.; Kaufman, P.E. Black soldier fly Hermetia illucens linnaeus (insecta: Diptera: Stratiomyidae). EENY 2009, 461, 1-3.

26. Ushakova, N.; Brodskii, E.; Kovalenko, A.; Bastrakov, A.; Kozlova, A.; Pavlov, D. Characteristics of Lipid Fractions of Larvae of the Black Soldier Fly Hermetia Illucens; Doklady Biochemistry and Biophysics; Springer: Berlin, Germany, 2016; pp. 209-212.

27. Caruso, D.; Devic, E.; Subamia, I.; Talamond, P.; Baras, E. Technical Handbook of Domestication and Production of Diptera Black Soldier Fly (bsf), Hermetia Illucens, Stratiomyidae; PT Penerbit IPB Press: Bogor, Indonesia, 2014.

28. Diener, S.; Lalander, C.; Zuebrueg, C.; Vinnerås, B. Opportunities and constraints for medium-scale organic waste treatment with fly larvae composting. In Proceedings of the 15th International Waste Management and Landfill Symposium, Cagliari, Italy, 5-9 October 2015.

29. Li, S.; Ji, H.; Zhang, B.; Tian, J.; Zhou, J.; Yu, H. Influence of black soldier fly (Hermetia illucens) larvae oil on growth performance, body composition, tissue fatty acid composition and lipid deposition in juvenile jian carp (cyprinus carpio var. Jian). Aquaculture 2016, 465, 43-52. [CrossRef]

30. Li, S.; Ji, H.; Zhang, B.; Zhou, J.; Yu, H. Defatted black soldier fly (Hermetia illucens) larvae meal in diets for juvenile jian carp (cyprinus carpio var. Jian): Growth performance, antioxidant enzyme activities, digestive enzyme activities, intestine and hepatopancreas histological structure. Aquaculture 2017, 477, 62-70. [CrossRef]

31. Leong, S.Y.; Kutty, S.R.M.; Malakamad, A.; Tan, C.K. Feasibility study of biodiesel production using lipids of Hermetia illucens larva fed with organic waste. Waste Manag. 2016, 47, 84-90. [CrossRef]

32. Nguyen, T.T.X.; Tomberlin, J.K.; Vanlaerhoven, S. Ability of black soldier fly (diptera: Stratiomyidae) larvae to recycle food waste. Environ. Entomol. 2015, 44, 406-410. [CrossRef]

33. Abdul Khalil, H.P.S.; Siti Alwani, M.; Mohd Omar, A.K. Chemical composition, anatomy, lignin distribution and cell wall structure of malaysian plant waste fibers. BioResources 2006, 1, 220-232.

34. Chuah, T.G.; Wan Azlina, A.G.K.; Robiah, Y.; Omar, R. Biomass as the renewable energy sources in malaysia: An overview. Int. J. Green Energy 2006, 3, 323-346. [CrossRef]

35. Jones, D.B. Factors for Converting Percentages of Nitrogen in Foods and Feeds into Percentages of Proteins; US Department of Agriculture: Washington, DC, USA, 1941.

36. Fathurochim, S.; Geden, C.J.; Axtell, R.C. Filth fly (diptera) oviposition and larval development in poultry manure of various moisture levels. J. Entomol. Sci. 1989, 24, 224-231. [CrossRef]

37. Kim, W.; Bae, S.; Park, H.; Park, K.; Lee, S.; Choi, Y.; Han, S.; Koh, Y.-H. The larval age and mouth morphology of the black soldier fly, Hermetia illucens (diptera: Stratiomyidae). Int. J. Ind. Entomol. 2010, 21, 185-187.

38. Lalander, C.; Diener, S.; Zurbrügg, C.; Vinnerås, B. Effects of feedstock on larval development and process efficiency in waste treatment with black soldier fly (Hermetia illucens). J. Clean. Prod. 2019, 208, 211-219. [CrossRef]

39. Draczyński, Z. Honeybee corpses as an available source of chitin. J. Appl. Polym. Sci. 2008, 109, $197-1981$. [CrossRef]

40. Zheng, L.; Li, Q.; Zhang, J.; Yu, Z. Double the biodiesel yield: Rearing black soldier fly larvae, Hermetia illucens, on solid residual fraction of restaurant waste after grease extraction for biodiesel production. Renew. Energy 2012, 41, 75-79. [CrossRef] 
41. Lim, J.-W.; Mohd-Noor, S.-N.; Wong, C.-Y.; Lam, M.-K.; Goh, P.-S.; Beniers, J.; Oh, W.-D.; Jumbri, K.; Ghani, N.A. Palatability of black soldier fly larvae in valorizing mixed waste coconut endosperm and soybean curd residue into larval lipid and protein sources. J. Environ. Manag. 2019, 231, 129-136. [CrossRef]

42. Makkar, H.P.S.; Tran, G.; Heuzé, V.; Ankers, P. State-of-the-art on use of insects as animal feed. Anim. Feed Sci. Technol. 2014, 197, 1-33. [CrossRef]

43. Spranghers, T.; Ottoboni, M.; Klootwijk, C.; Ovyn, A.; Deboosere, S.; De Meulenaer, B.; Michiels, J.; Eeckhout, M.; De Clercq, P.; De Smet, S. Nutritional composition of black soldier fly (Hermetia illucens) prepupae reared on different organic waste substrates. J. Sci. Food Agric. 2016, 97, 2594-2600. [CrossRef]

44. Waśko, A.; Bulak, P.; Polak-Berecka, M.; Nowak, K.; Polakowski, C.; Bieganowski, A. The first report of the physicochemical structure of chitin isolated from Hermetia illucens. Int. J. Biol. Macromol. 2016, 92, 316-320. [CrossRef]

45. Diener, S.; Zurbrügg, C.; Gutiérrez, F.R.; Nguyen, D.H.; Morel, A.; Koottatep, T.; Tockner, K. In Black soldier fly larvae for organic waste treatment-prospects and constraints. In Proceedings of the 2nd International Conference on Solid Waste Management in the Developing Countries, Khulna, Bangladesh, 13-15 February 2011.

46. Upadhaya, S.D.; Lee, K.Y.; Kim, I.H. Effect of protected organic acid blends on growth performance, nutrient digestibility and faecal micro flora in growing pigs. J. Appl. Anim. Res. 2016, 44, 238-242. [CrossRef]

47. Rehman, K.u.; Rehman, A.; Cai, M.; Zheng, L.; Xiao, X.; Somroo, A.A.; Wang, H.; Li, W.; Yu, Z.; Zhang, J. Conversion of mixtures of dairy manure and soybean curd residue by black soldier fly larvae (Hermetia illucens L.). J. Clean. Prod. 2017, 154, 366-373. [CrossRef]

48. Surendra, K.C.; Oliver, R.; Tomberlin, J.K.; Jha, R.; Khanal, S.K. Bioconversion of organic wastes into biodiesel and animal feed via insect farming. Renew. Energy 2016, 98, 197-202. [CrossRef]

49. Zheng, L.; Hou, Y.; Li, W.; Yang, S.; Li, Q.; Yu, Z. Biodiesel production from rice straw and restaurant waste employing black soldier fly assisted by microbes. Energy 2012, 47, 225-229. [CrossRef]

50. Li, Q.; Zheng, L.; Qiu, N.; Cai, H.; Tomberlin, J.K.; Yu, Z. Bioconversion of dairy manure by black soldier fly (diptera: Stratiomyidae) for biodiesel and sugar production. Waste Manag. 2011, 31, 1316-1320. [CrossRef]

(C) 2019 by the authors. Licensee MDPI, Basel, Switzerland. This article is an open access article distributed under the terms and conditions of the Creative Commons Attribution (CC BY) license (http://creativecommons.org/licenses/by/4.0/). 